\title{
New occurence of the Cambrian (Stage 4, Series 2) Guanshan Biota in Huize, Yunnan, South China
}

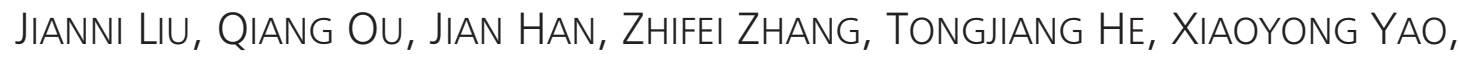 \\ DONGIING FU \& DEGAN SHU
}

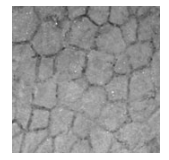

\begin{abstract}
Typical elements of the Guanshan Biota are reported from the Cambrian Stage 4 Wulongqing Formation of Huize, Qujing, South China, approximately $100 \mathrm{~km}$ north of the Guanshan fossil sites previously reported. Lithostratigraphy and biostratigraphy of the current Zhujiaqing section are also discussed herein. Representatives of various phyla recovered therein include not only previously described sponges, palaeoscolecids, arthropods, brachiopods, echinoderms, and vetulicolians, but also some potential new taxa, e.g. a new species of Vetulicola. This new occurrence not only expands the palaeogeographic distribution of the Guanshan Biota, but also strengthens the ties between the younger Chengjiang Biota and the older Kaili Biota (and also the coeval Burgess Shale community). - Key words: Guanshan Biota, lower Cambrian, China.
\end{abstract}

\begin{abstract}
LIU, J.N, OU, Q., HAN, J., ZHANG, Z.F., HE, T.J., YAO, X.Y., FU, D.J. \& SHU, D.G. 2012. New occurence of the Cambrian (Stage 4, Series 2) Guanshan Biota in Huize, Yunnan, South China. Bulletin of Geosciences 87(1), 125-132 (4 figures). Czech Geological Survey, Prague. ISSN 1214-1119. Manuscript received September 22, 2010; accepted in revised form August 4, 2011; published online February 29, 2012; issued February 29, 2012.

Jianni Liu (corresponding author), Early Life Institute and Key Laboratory of Continental Dynamics, Northwest University, Xi'an 710069, P. R. China \& Department of Earth Science, Freie Universität Berlin, Malteserstr. 74-100, Haus D, 12249, Berlin, Germany; liujianni@ 126.com•Qiang Ou, Early Life Evolution Laboratory, School of Earth Sciences and Resources, China University of Geosciences, Beijing 100083, P.R. China; ouqiang@cugb.edu.cn・Jian Han, Early Life Institute and Key Laboratory of Continental Dynamics, Northwest University, Xi'an 710069, P. R. China; elihanj@nwu.edu.cn•Zhifei Zhang, Early Life Institute and Key Laboratory of Continental Dynamics, Northwest University, Xi'an 710069, P. R. China; elizf@nwu.edu.cn・Tongjiang He, Department of Geology, Northwest University, Xi'an 710069, P. R. China; hhttjj@126.com -Xiaoyong Yao, Department of Geology, Northwest University, Xi'an 710069, P. R. China; redsmall1982@sina.com •Dongjing Fu, Department of Geology, Northwest University, Xi'an 710069, P. R. China; fudongjing2007@yahoo.com.cn・Degan Shu, Early Life Institute and Key Laboratory of Continental Dynamics, Northwest University, Xi'an 710069, P. R. China; elidgshu@nwu.edu.cn
\end{abstract}

Trilobites Palaeolenus lantenoisi and Palaeolenus douvillei from the Cambrian Stage 4 Wulongqing Formation were first reported by Mansuy (1912) and subsequently restudied (Lu 1961, 1962; Luo 1974; Luo et al. 1994; Zhang 1966; Zhang et al. 1980). The bivalved arthropod Tuzoia sinensis Pan was first described by Pan (1957) from the lower part of the Wulongping Formation (Canglangpu Stage). Brachiopods (Rong 1974) and bradoriids (Zhang 1974, Li 1975) from the same horizon were also described earlier on.

Non-trilobite arthropods and palaeoscolecids worms were first recovered in 1995 from yellow-greenish shale of the lower Wulongqing Formation in Gangtoucun section of Kunming, Yunnan (Luo et al. 1999). Excavation (1996) in the Lihuazhuang section of the same level in Yiliang, Yunnan, yielded more abundant arthropods, including the phyllocarid Yiliangocaris ellipticus Luo \& $\mathrm{Hu}$, the brachiopod Branchiocaris sp., eumalacostracans Habelia sp. (?), and trilobites Redlichia mansuyi Resser \& Endo and Palaeolenus douvillei Mansuy, preserved together with abundant brachiopod specimens of Diandongia pista Rong (Luo et al. 1999). Accordingly, Luo et al. (1999) grouped them into the so-called Guanshan Biota, and subsequently investigated the vetulicolian Vetulicola gangtoucunensis Luo, Fu \& Hu, arthropods Tuzoia tylodesa Luo \& Hu, and Isoxys wudingensis Luo \& Hu.

Li et al. (2006) reviewed the Guanshan Biota and concluded that it is a Burgess Shale-type Biota consisting mainly of arthropods (accounting for ca 65\% in abundance) and other animals (in particular vetulicolians, brachiopods, worms, and sponges, each group accounting for ca 8\%). Hu et al. (2007) reported eocrinoid echinoderms Wudingeocrinus rarus $\mathrm{Hu} \&$ Luo from the Wulongqing Formation in Wuding, Yunnan. This finding 


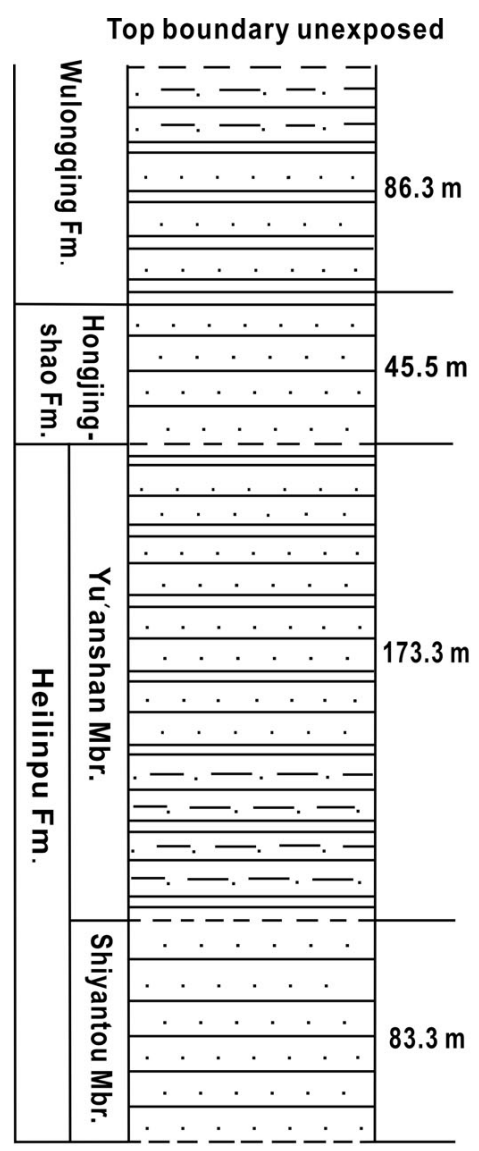

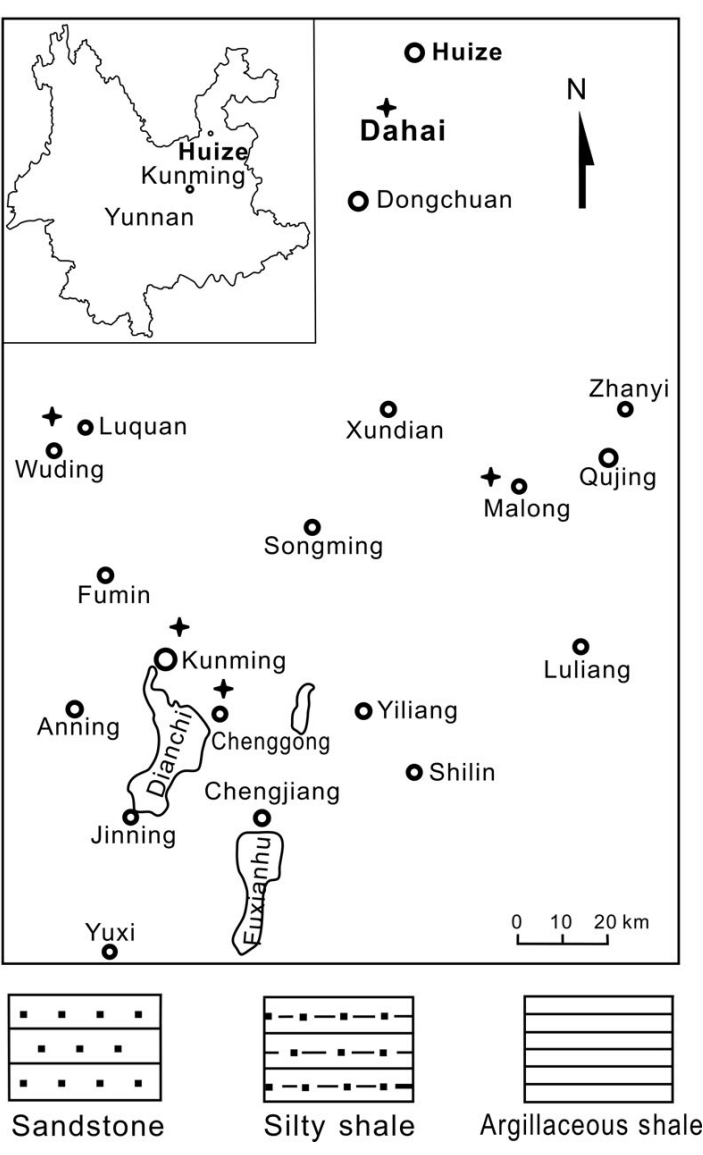

Figure 1. Synthesized stratigraphic column of the Zhujiaqing section (Series 2, Stage 4, Cambrian) in Dahai village, Huize, Yunnan and the main occurences of Guanshan Biota in Yunnan, southwest China. further enriches the biodiversity of the biota with a phylum-grade group that has significant implications for the origin and ecology of early echinoderms. In addition, more counterparts of the Chengjiang and the Burgess Shale representatives were recently revealed in the Guanshan Biota, including the lobopodian Hallucigenia sp., medusoid form Eldonia sp., and hyolithid Linevitus malongensis with preserved helens, green algae, Phlogites, linguliform brachiopod Acanthotretella with soft-part (Hu et al. 2010a-c), and basal deuterostome Vetulicola longbaoshanensis (Yang et al. 2010).

\section{New occurrence of Guanshan Biota in Huize}

\section{Geological and stratigraphical framework}

The Guanshan Biota occurs in the Wulongqing Formation of early Cambrian, which is widely distributed in eastern Yunnan, e.g. Kunming-Wuding and Malong-Yiliang area; the best studied sections are Gangtoucun and Gaoloufang of Kunming, Sapushan of Wuding, Lihuazhuang of Yiliang and Wulongqing of Malong (Fig. 1). During a geological survey in 2007, we recovered a specimen of palaeoscolecid worm, an index of soft-tissue preservation, from the lower part of the Wulongqing Formation in Zhujiaqing section of Dahai village, Huize, Yunnan (Fig. 1). Subsequent systematic excavation revealed that it is a typical Guanshan fossil Lagerstätte which demonstrates the extensive distribution of the biota and is promising in further deciphering the evolution and diversification of the biota.

The basal Cambrian succession in the Zhujiaqing section in Dahai village, Huize, consists of, in ascending order, the Heilinpu Formation (subdivided into the Shiyantou Member and Yu'anshan Member), Hongjingshao Formation, and Wulongqing Formation (Fig. 1). Generally, as Luo et al. (2008) indicated, the Guanshan Biota occurs from the base and continuously to the uppermost Wulongqing Formation, and the fossils are much richer in basal part than upper part. However, the top boundary of Wulongqing Formation is unexposed in this Zhujiaqing section. The Wulongqing Formation in Zhujiaqing section, with a measured thickness of $\sim 86$ meters, is mainly composed of yellow-greenish, thin-bedded argillaceous shale, where Guanshan fossils are prone to preserved, and grey-yellowish, thin-bedded silty shale. The fossiliferous deposits of Zhujiaqing section can be subdivided into two zones: the lower part with a biased poor bio-diversification, mainly composed of biomineralized or sclerotized 

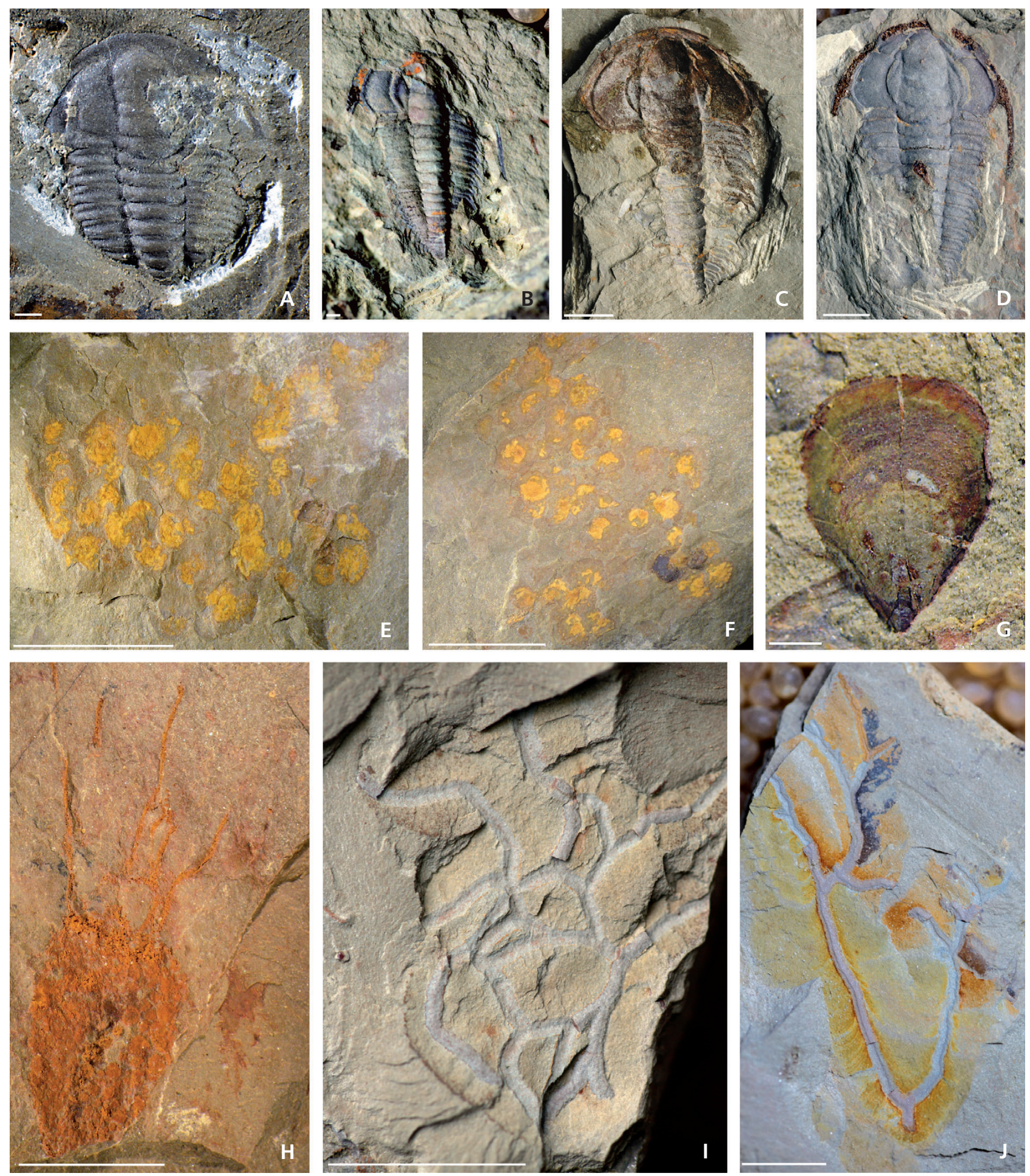

Figure 2. Some representatives of the Guanshan Biota in Huize, Yunnan. • A - trilobite Palaeonlenus douvillei Mansuy, 1912 (ELI-HZ-P-001A). - B, C - trilobite Redlichia noetlingi Redlich, 1899 (ELI-HZ-RN-001A). • D - trilobite Redlichia mansuyi Resser \& Endo, 1937? (ELI-HZ-RM-001A). - E, F - the sponge Crumillospongia biporosa Rigby, 1986 (ELI-HZ-C-001). • G - brachiopod Lingulellotreta malongensis Rong, 1974 (ELI-HZ-B-001). • H - echinoderm Wudingeocrinus rarus Hu \& Luo, 2007 (ELI-HZ-W-001). $・$ I, J - an unknown trace fossil (ELI-HZ-TF-001 A, B). Scale bars in A, B and $\mathrm{G}$ are in $\mathrm{mm}$, others are in $\mathrm{cm}$. 
shells of trilobites and brachiopods with rare preservation of soft parts; the upper part with much richer diversification, containing vetulicolians, palaeoscolecids, sponges, tentaculate eocrinoids etc., most of which are preserved with soft parts. Compared with the biozones of other Guanshan Biota, the two zones of Zhujiaqing section probably both belong to Palaeolenus zone (Luo et al. 2008), which occurs in the basal part of Wulongqing Formation; in other words, the two zones of Zhujiaqing probably is a sub-division of the Guanshan Biota because the top boundary of Wulongqing Formation is unexposed in this Zhujiaqing section. Similar to the preservation of other localities of Guanshan Biota, the fossils in Huize are mostly autochthonous or parautochthonous assemblages buried in situ or with minimum transportation.

\section{New fossil data}

A total of over 500 specimens belonging to various phyla were recovered from the new fossil locality, covering the bulk of reported metazoan taxa from the biota. Arthropods and brachiopods are the most abundant taxa, followed by palaeoscolecid worms, eocrinoid echinoderms, and vetulicolians. Here show some typical representative species: the trilobites Palaeonlenus douvillei Mansuy (Fig. 2A), Redlichia cf. noetlingi (Redlich) (Fig. 2B, C), Redlichia mansuyi (Redlich)? (Fig. 2D), possibly the sponge Crumillospongia biporosa Rigby (Fig. 2E, F); the brachiopod Lingulellotreta malongensis (Fig. 2G); the echinoderm Wudingeocrinus rarus $\mathrm{Hu} \& \mathrm{Luo}$ (Fig. $2 \mathrm{H}$ ); some unknown trace fossils (Fig. 2I, J); the non-trilobite arthropod Tuzoia sinensis Pan (Fig. 3A-E); the palaeoscolecid Guanduscolex minor $\mathrm{Hu}$, Luo \& Fu (Fig. 3F-I); the vetulicolian Vetulicola gangtoucunensis Luo, Fu \& Hu (Fig. 3M, N); and the assemblage of brachiopods (Fig. 3O).

Still noteworthy is the currently discovered vetulicolians of potential deuterostome affinity (Shu et al. 2001, 2005, 2010). In addition to Vetulicola gangtoucunensis (Luo et al. 2005; Fig. 3M, N), a few specimens of vetulicolians with some distinct characters, based on which they could probably be assigned to a new species, are also recovered during this work. Compared to Vetulicola gangtoucunensis, they are of smaller size, with the mouth less squared, the lateral groove seemingly undulated (Fig. 3I, K), and the posterior section comparatively slen- der, with lateral blades of the distal segments being less broad (Fig. 3L), which also differs from the recently reported Vetulicola longbaoshanensis (Yang et al. 2010) from Kunming, Yunnan.

Another interesting fossil is palaeoscolecid worm, we found four cuticular fragmental specimens of palaeoscolecid worms which are greatly compressed. Our scanning electron microscopy (SEM) analysis revealed that two of them (ELI-HZ-G-001A, B and ELI-HZ-G-002A, B) preserved with detail ornaments of the external cuticles (Fig. 4). The trunk of the first specimen (ELI-HZ-G-001) is cylindrical and straight, $c a 2 \mathrm{~mm}$ in diameter; the gut is represented by dark strand (Fig. $3 \mathrm{~F}, \mathrm{G}$ ). The trunk is unevenly and tightly annulated due to strongly and longitudinally contracting of the body. Each annulation bears seemingly one or two transverse rows of circular or sub-circular plates. These plates are rather closely spaced in each row. A single plate, $c a 30 \mu \mathrm{m}$ in diameter, with strongly convex upper surface covered by uniformly 6 nodes surrounded by a lower and wider smooth margin. Apparently, this plate is distinct from Guanduscolex minor $\mathrm{Hu}$, Luo \& Fu, 2008 but similar to Palaeoscolex spinosus Ivantsov \& Wrona, 2004, however, the plates of the latter occasionally bears a central nodes (Ivantsov \& Wrona 2004) and are more loosely arrayed than the second specimen.

The second specimen (ELI-HZ-G-002) preserved most part of the trunk and the trunk end. The trunk slightly tapers backward and approximately 3-4 $\mathrm{mm}$ in diameter. This specimen is sinuously curved and lack any imprint of gut (Fig. 3H, I), seemingly the shedding molts of the animal. The trunk is finely annulated, with about 4 annulations per millimeter. Each annulation bears two transverse rows of circular plates with strongly convex upper surface which reversely appeared as concaved structures (Fig. 4C, D). The plates are ca $30 \mu \mathrm{m}$ in diameter. The surface ornament of the plates was obscure in most case due to poor preservation; rarely, they were found bearing 4 or 5 nodes (Fig. 4E, F). These plates in the neighboring rows are arranged in a staggering pattern so as to increase the friction against the substrates, and this pattern could also avoid colliding when the trunk is strongly contracted along the anterior-posterior body axial. All these features suggested that this specimen resembles Guanduscolex minor $\mathrm{Hu}$, Luo \& Fu, 2008, although the latter species bears additional 9 marginal nodes arranged in a circlet around 4-5 central nodes.

Figure 3. Some representatives of the Guanshan Biota in Huize, Yunnan. - A-E - non-trilobite arthropod Tuzoia sinensis Pan, 1957 (ELI-HZ-T-001A, B, 002, 003). • F, G - palaeoscolecid Palaeoscolex spinosus Ivantsov \& Wrona, 2004? (ELI-HZ-G-001A, B). • H, I-palaeoscolecid Guanduscolex minor Hu, Luo \& Fu, 2008 (ELI-HZ-G-001A, B). • J-L - a new species of vetulicolian (ELI-HZ-V-001A, B, and ELI-HZ-V-002, respectively). $\bullet$ M, N - Vetulicola gangtoucunensis Luo, Fu \& Hu, 2005 (ELI-HZ-V-003A, B). • O - the assemblage of brachiopods (ELI-HZ-B-002). Scale bars in F, G, J and $\mathrm{K}$ are in $\mathrm{mm}$, others are in $\mathrm{cm}$. 

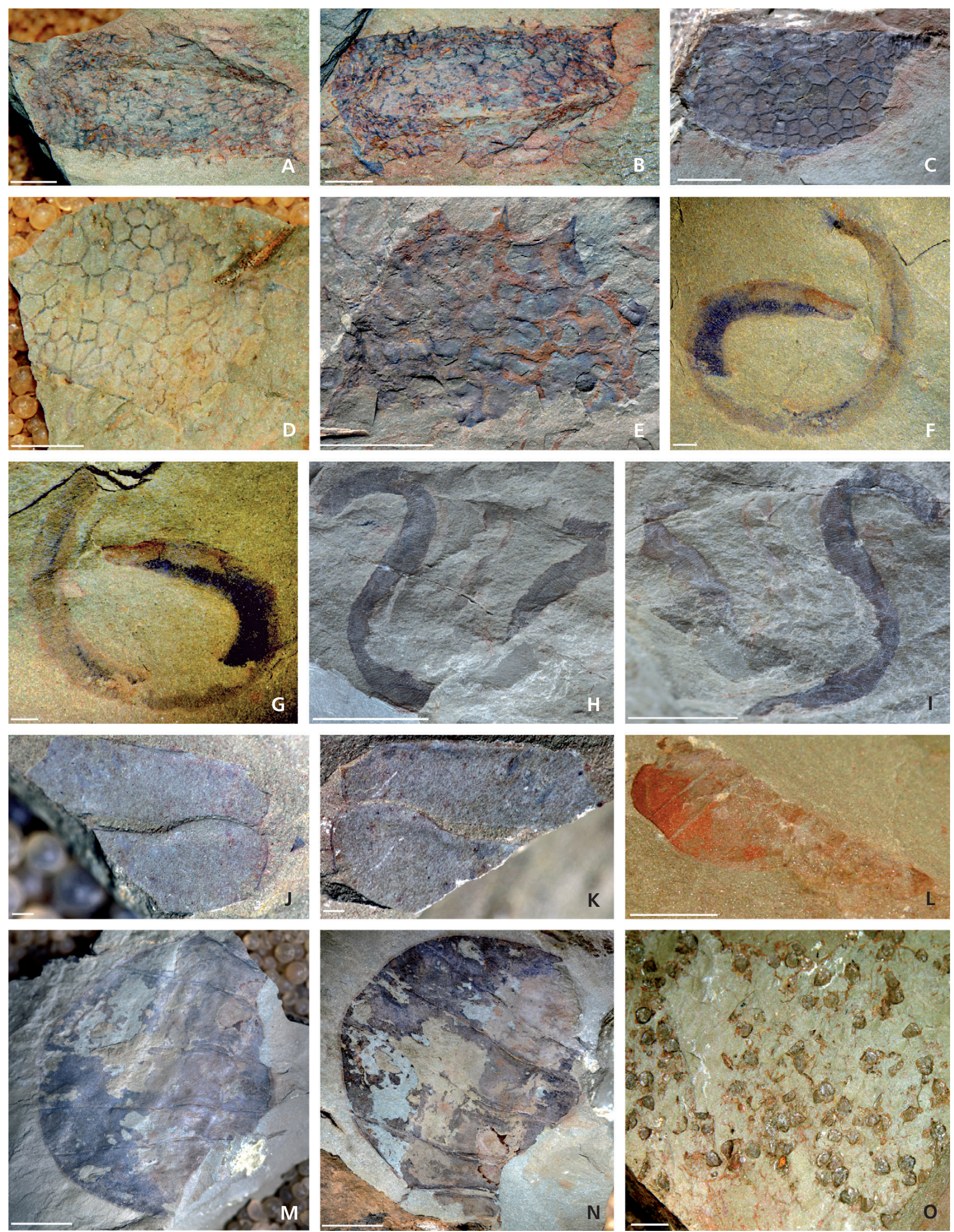

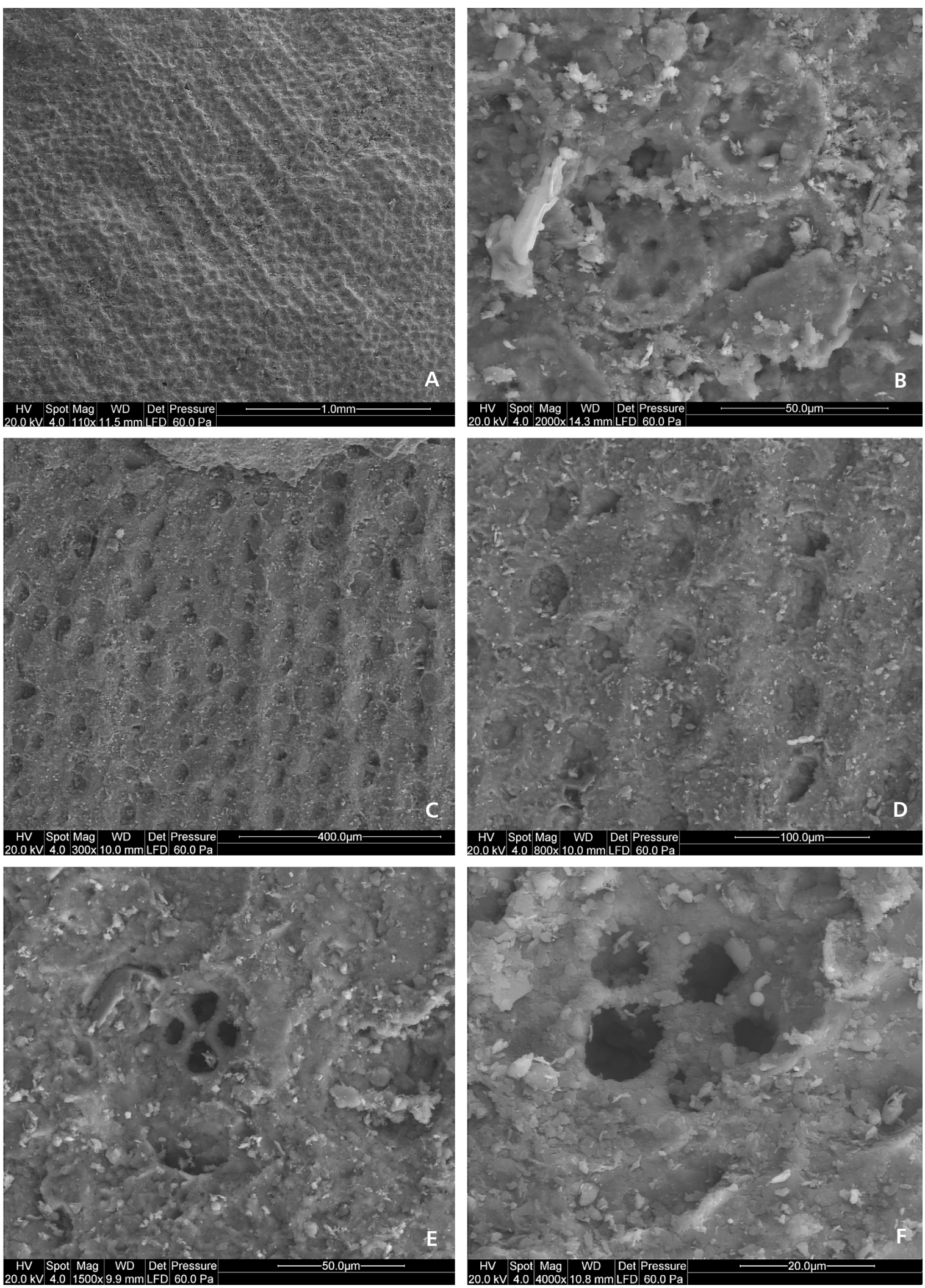

Figure 4. Palaeoscolecid worms from the lower Cambrian Wulongqing Formation at the Dahai, Huize sections, Yunnan Province, China. • A - SEM pictures showing the trunk annulations of palaeoscolecid worm ELI-HZ-G-001A. $\bullet$ B - close-up showing of three closely packed plates in a transverse row of ELI- HZ-G-001A. • C, D - SEM pictures showing the trunk annulations of palaeoscolecid worm ELI-HZ-G-002A. • E, F - enlargement of the plates with nodes of ELI-HZ-G-002A. 


\section{Discussion and conclusions}

The Guanshan Biota (Cambrian Series 2, Stage 4, ca 515-510 Ma) serves as an evolutionary bridge closely linking the older Chengjiang (Cambrian Series 2, Stage 3) and the younger Kaili Biota (Cambrian Series 3, Stage 5 also coeval to Burgess Shale Biota), it has significant implications for our understanding of the chronology of the Cambrian radiation and its aftermath.

Compared with previously reported fossil sites (Kunming-Wuding, Malong-Yiliang; see $\mathrm{Hu}$ et al. 2010), the new occurrence of the Guanshan Biota in Huize area expands its biogeographic distribution approximately $100 \mathrm{ki}-$ lometers northwards. This work, thus, provides a new vista not only for research of the Guanshan palaeobiology, but also for investigation of its palaeoecology, palaeoenvironment, and palaeobiogeography. Furthermore, the new data presented here emphasize the importance of the Guanshan Biota as a key-element in the chronology of the Cambrian radiation between its early steps exemplified by the Chengjiang Biota and its aftermath.

\section{Acknowledgments}

We thank the anonymous referees for constructive criticism. Financial support for this study was provided by a Research Scholarship of Alexander von Humboldt Foundation at FU Berlin, the National Natural Science Foundation of China (Grant No. 41172023, 40802011, 40602003, 40830208), National 973 Project (2006CB806401), the MOST Special Fund from the State Key Laboratory of Continental Dynamics, Northwest University, the Program for Changjiang Scholars and Innovative Research Team in University (PCSIRT), Research Fund for the Doctoral Program of Higher Education (RFDP), Innovative Education Program for Graduate Students in the Northwest University (07YYB02).

\section{References}

Hu, S.X., Li, Y., LuO, H.L., Fu, X.P., You, T., PANG, J.Y., Liu, Q. \& STEINER, M. 2008. New record of palaeoscolecids from the Early Cambrian of Yunnan, China. Acta Geologica Sinica 82(2), 244-248. DOI 10.1111/j.1755-6724.2008.tb00574.x

Hu, S.X., Li, X.K., TAN, X.H., Zhan, D.Q. \& LuO, H.L. 2010 b. Phlogites from the Early Cambrian Guanshan Fauna. Acta Palaeontologica Sinica 49(3), 360-364.

Hu, S.X., Luo, H.L., Hou, S.G. \& Erdtmann, B.-D. 2007. Eocrinoid echinoderms from the Lower Cambrian Guanshan Fauna in Wuding, Yunnan, China. Chinese Science Bulletin 52(5), 717-719. DOI 10.1007/s11434-007-0083-6

Hu, S.X., Zhang, Z.F., Holmer, L.E. \& Skovsted, C.B. 2010c. Soft-part preservation in a linguliform brachiopod from the lower Cambrian Wulongqing Formation (Guanshan Fauna) of
Yunnan, South China. Acta Palaeontologica Polonica 55(3), 495-505. DOI 10.4202/app.2009.1106

Hu, S.X., Zhu, M.Y., Steiner, M., Luo, H.L., Zhao, F.C. \& Liu, Q. 2010a. Biodiversity and taphonomy of the early Cambrian Guanshan biota, eastern Yunnan. Science China - Earth Sciences 53(12), 1765-1773. DOI 10.1007/s11430-010-4086-9

Ivantsov, A.Y. \& WronA, R. 2004. Articulated palaeoscolecid sclerite arrays from the Lower Cambrian of eastern Siberia. Acta Geologica Polonica 54(1), 1-22.

Li, Y.W., Chen, L.Z., Luo, H.L., Fu, X.P., Hu, S.X., You, T. \& Liu, Q. 2006. New advances in the study of the Early Cambrian Guanshan fauna in the Kunming area, Yunnan, China. Geological Bulletin of China 25(3), 415-418.

LI, Y.W. 1975. Cambrian ostracode and new occurrence in Sichuan, Yunnan and Shaanxi Province [A]. Proceedings on Palaeontology and Stratigraphy C 2, 37-72. [in Chinese]

Lu, Y.H. 1961. New Lower Cambrian trilobites from eastern Yunnan. Acta Palaeontologica Sinica 9(4), 299-328.

Lu, Y.H. 1962. The Cambrian system of China, 1-117. Scientific Report of the $1^{\text {st }}$ All China Conference on Stratigraphy. Science Press, Beijing. [in Chinese]

Luo, H.L. 1974. The illustrated books offossils from Yunnan (The trilobite), 597-694. Yunnan Science and Technology Press, Kunming. [in Chinese]

Luo, H.L., Fu, X.P., Hu, S.X., Li, Y., Chen, L.Z., You, T. \& LiU, Q. 2005. New vetulicoliids from the Lower Cambrian Guanshan Fauna, Kunming. Acta Geologica Sinica 79(1), 1-6. DOI 10.1111/j.1755-6724.2005.tb00860.x

LuO, H.L., Fu, X.P., Hu, S.X., Li, Y., ChEn, L.Z., You, T. \& LiU, Q. 2006. New bivalved arthropods from the early Cambrian Guanshan fauna in the Kunming and Wuding area. Acta Palaeontologica Sinica 45(4), 460-472.

Luo, H.L., Hu, S.X., Chen, L.Z., Zhang, S.S. \& TAO, Y.H. 1999. Early Cambrian Chengjiang Fauna from Kunming region, China. 129 pp. Yunnan Science and Technology Press, Kunming. [in Chinese with English summary]

LuO, H.L., JiANG, Z.W. \& TANG, L.D. 1994. Stratotype Section for Lower Cambrian Stages in China. 183 pp. Yunnan Science and Technology Press, Kunming. [in Chinese]

Luo, H.L., Li, Y., Hu, S.X., Fu, X.P., Hou, S.G., Liu, X.R., Chen, L.Z., Li, F.J., PANG, J.Y. \& Liu, Q. 2008. Early Cambrian Malong Fauna and Guanshan Fauna from Eastern Yunnan, China. 122 pp. Yunnan Science and Technology Press, Kunming. [in Chinese with English summary]

Mansuy, H. 1912. Etude géologique de Yunnan Oriental. Pt. 2. Palaeontogie. Mémoires du Service Géologique de L'Indochine 1(2), 1-146.

PAN, J. 1957. On the discovery of homopoda from South China. Acta Palaeontologica Sinica 5(4), 523-526.

ReduICH, K. 1899. The Cambrian fauna of the eastern Salt Range. Memories of the Geological Survey of India, Palaeontologica India, New Series 1, 1-13.

Resser, C.E. \& Endo, R. 1937. The Sinian and Cambrian formations and fossils of southern Manchoukuo. Manchurian Science Museum Bulletin 1, 1-474. 
Rigby, J.K. 1986. Sponges of the Burgess Shale (Middle Cambrian), British Columbia. Paleontographica Canadiana 2, $1-105$.

Rong, J.Y. 1974. Cambrian brachiopods, 113-114. In NANJiNG Institute of Geology and Palaeontology, Academia Sinica (ed.) Handbook of palaeontology and stratigraphy of southwest China. Science Press, Beijing. [in Chinese]

Shu, D.G. 2005. On the phylum Vetulicolia. Chinese Sciences Bulletin 50, 2342-2354.

Shu, D.G., Conway Morris, S., Han, J., Chen, L., Zhang, X.L., Zhang, Z.F., LiU, H.Q., Li, Y. \& LiU, J.N. 2001. Primitive deuterostomes from the Chengjiang Lagerstätte (Lower Cambrian, China). Nature 414, 419-424.

DOI 10.1038/35106514

Shu, D.G., Conway Morris, S., Zhang, Z.F. \& Han, J. 2010. The earliest history of the deuterostomes: the importance of the Chengjiang Fossil-Lagerstätte. Proceeding of Royal So- ciety of London B277, 165-174.

DOI 10.1098/rspb.2009.0646

Yang, J., Hou, X.G., Cong, P.Y., Dong, W., Zhang, Y.X. \& LuO, M.B. 2010. A new vetulicoliid from lower Cambrian, Kunming, Yunnan. Acta Palaeontologica Sinica 49(1), 54-63.

Zhang, W.T. 1966. On the classification of Redlichiacea, with description of new families and new genera. Acta Palaeontologica Sinica 14(2), 135-184. [in Chinese with English summary]

Zhang, W.T. 1974. Cambrian ostracode, 107-111. In NANJING INstitute of Geology, Academia Sinica (ed.) Handbook of palaeontology and stratigraphy of southwest China. 454 pp. Science Press, Beijing. [in Chinese]

Zhang, W.T., Lu, Y.H., Zhu, Z.L., Qian, Y.Y., Lin, H.L., Zhou, Z.Y., ZhanG, S.G. \& YUAN, J.L. 1980. Cambrian trilobite faunas of southwestern China. Palaeontologica Sinica 159, New Series $B 16$. 